Check for updates

Cite this: Chem. Sci., 2019, 10, 3632

๑ All publication charges for this article have been paid for by the Royal Society of Chemistry

Received 20th December 2018

Accepted 18th February 2019

DOI: $10.1039 / \mathrm{c} 8 \mathrm{sc} 05689 \mathrm{~g}$

rsc.li/chemical-science

\section{Copper-catalyzed 1,4-alkylarylation of 1,3-enynes with masked alkyl electrophiles $\dagger$}

\author{
Changqing Ye, ${ }^{\text {ab }}$ Yajun Li, (D) a Xiaotao Zhu, ${ }^{a}$ Shengmin $\mathrm{Hu}^{a}$ Daqiang Yuan (D) a \\ and Hongli Bao (D)*ab
}

Classical 1,4-dicarbofunctionalization of 1,3-enynes employs organometallic reagents as nucleophiles to initiate the reaction. We report a copper-catalyzed 1,4-alkylarylation of 1,3-enynes with alkyl diacyl peroxides as masked alkyl electrophiles and aryl boronic acids as nucleophiles, selectively affording structurally diversified tetrasubstituted allenes under mild conditions. Mechanistic studies suggest that an allenyl radical might be involved.
Allenes are important structural motifs found in natural products and are key intermediates in the synthesis of complex and bioactive molecules. ${ }^{1}$ Useful methods ${ }^{1 d, 2}$ for the synthesis of allenes include molecular rearrangement, ${ }^{3}$ nucleophilic substitution, ${ }^{4} 1,4$-addition ${ }^{5}$ and other methods. ${ }^{6}$ Among these methods, 1,4-difunctionalization of 1,3-enynes is particularly appealing because it enables two functionalities to be incorporated simultaneously. Regioselective introduction of an alkyl and an aryl group into allene moieties is of great interest as it can significantly diversify the structures of the resulting allenes. There is however only one example of 1,4-alkylarylation of 1,3enynes. In this reaction, developed by Ma et al. (Fig. 1a), alkyl lithium reagents were used as nucleophiles to initiate the reaction, followed by $\mathrm{Li}-\mathrm{Zn}$ exchange and cross coupling with aryl halides serving as the electrophiles. Allenyl anions were proposed as the intermediates. Using alkyl-metallic reagents, groups led by Kambe, ${ }^{8}$ Yoshida, ${ }^{9}$ and Kimura ${ }^{5 e}$ have developed efficient 1,4-dicarbofunctionalizations of 1,3-enynes with other electrophiles.

Although alkyl-metallic reagents are highly reactive, there are some limitations associated with such compounds. For example, organometallic reagents are sensitive to moisture and reactions involving them usually have low functional group compatibilities both in the organometallic reagents and in other reaction partners. To meet the needs of alkylating reactions in organic synthesis, several non-traditional types of alkylating reagents, including alkyl boronates, ${ }^{10}$ redox-active

${ }^{a}$ Key Laboratory of Coal to Ethylene Glycol and Its Related Technology, State Key Laboratory of Structural Chemistry, Center for Excellence in Molecular Synthesis, Fujian Institute of Research on the Structure of Matter, 155 Yangqiao Road West, Fuzhou, Fujian 350002, P. R. China

${ }^{b}$ University of Chinese Academy of Sciences, No. 19(A) Yuquan Road, Shijingshan District, Beijing 100049, P. R. China. E-mail: hlbao@ffirsm.ac.cn

$\dagger$ Electronic supplementary information (ESI) available. CCDC 1883091. For ESI and crystallographic data in CIF or other electronic format see DOI: $10.1039 / \mathrm{c} 8 \mathrm{sc} 05689 \mathrm{~g}$ esters, ${ }^{11}$ and alkyl peroxides ${ }^{12}$ have been developed and studied recently.

Our previous studies revealed that alkyl peroxides generated from the corresponding alkyl carboxylic acids, can in the presence of a copper, ${ }^{13}$ iron $^{12}$ and HOTf ${ }^{14}$ catalyst act simultaneously as alkylating reagents and internal oxidants. Actually, the alkyl diacyl peroxides in a catalytic system can be simply regarded as masked alkyl electrophiles (Fig. 1b). Thus, we wondered whether alkyl peroxides can initiate the 1,4-alkylarylation reaction of 1,3-enynes to form allenes. This would offer an unprecedented strategy to allenes, most importantly, overcoming many of the difficulties associated with organometallic reagents.

Herein, we report that alkyl peroxides enable 1,4-alkylarylation of 1,3-enynes to form allenes, a reaction in which alkyl peroxides serve as the masked alkyl electrophiles and aryl boronic acids serve as nucleophiles (Fig. 1c). Mechanistic studies suggest that this reaction proceeds through an allenyl radical ${ }^{15}$ pathway, ${ }^{16}$ which is relatively rare in allene synthesis.

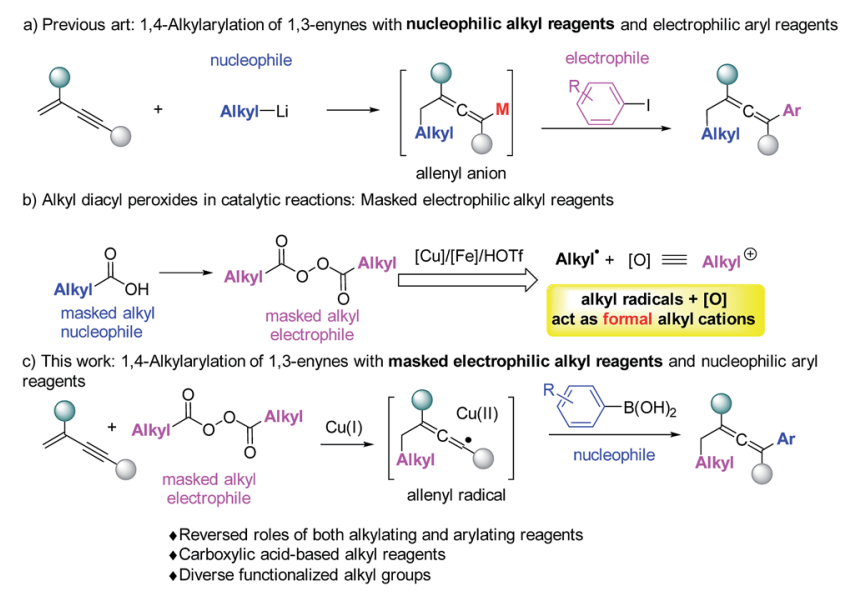

Fig. 1 1,4-Alkylarylation of 1,3-enynes. 
We initiated our studies by screening the reaction conditions employing a 1,3-enyne (1a), lauroyl peroxide (LPO, 2a) and phenylboronic acid (3a) as the starting materials and $N, N$-diisopropylethylamine (DIPEA) as a base (Table 1). The results of screening of the reaction conditions are detailed in the ESI. $\dagger$ Our experiments revealed that $\mathrm{Cu}\left(\mathrm{CH}_{3} \mathrm{CN}\right)_{4} \mathrm{BF}_{4}$ is optimal and the ligand is the key element for this reaction. As shown in Table 1, bipyridine ligands (L1-L4) show low reactivities, while phenanthrolines, phosphoramidite, Phox and bipyridine oxazoline ligands (L5-L9) fail to afford the desired product. Chiral bisoxazoline ligands (L10-L12) on the other hand, proven to be excellent ligands for the copper-catalyzed asymmetric synthesis of $\mathrm{CF}_{3}$-substituted 1,1-diarylethanes, but they show poor reactivity and enantioselectivity in the present reaction. ${ }^{17} \mathrm{~A}$ dramatic increase in the yield of the reaction was observed when tridentate Py-Box ligands (L13-L16) were used. Although the enantioselectivities are still not satisfactory for the chiral ligands, the reactivity for $\mathbf{L 1 6}$ is useful. Thus, $( \pm)$-L16 was studied, providing an identical yield (70\%).

With the optimal reaction conditions in hand, the substrate scope of 1,3-enynes was explored as shown in Table 2. Both electron-donating and electron-withdrawing substituents on the aromatic ring of $\mathrm{R}^{1}$ are suitable for this coupling reaction, which affords the tetrasubstituted allene products $(\mathbf{4 b} \mathbf{b}-\mathbf{4 h})$ in moderate to good yields (46-73\%). A naphthyl group is also compatible with this reaction, producing $4 \mathbf{i}$ in $54 \%$ yield. In the substituent $\mathrm{R}^{2}$ group, functional groups such as phenyl, cyclohexyl, ester, and free hydroxyl group are tolerated, giving the desired products $(\mathbf{4 j} \mathbf{j}-\mathbf{4 n})$ in $32-69 \%$ yields. Products $\mathbf{4 o}$ and $\mathbf{4 p}$ are obtained in $49 \%$ and $27 \%$ yields respectively, when $\mathrm{R}^{1}$ is

Table 1 Ligand screening ${ }^{a, b}$

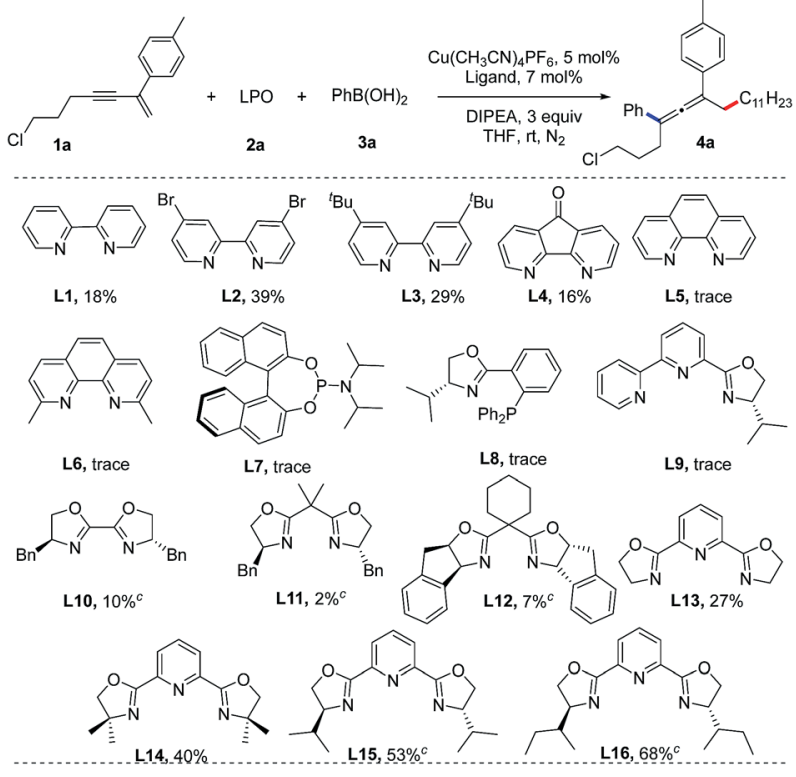

${ }^{a}$ Reaction conditions: 1a ( $0.2 \mathrm{mmol}, 1$ equiv.), $2 \mathrm{a}$ ( $0.3 \mathrm{mmol}, 1.5$ equiv.), 3a (0.6 mmol, 3 equiv.), $\mathrm{Cu}\left(\mathrm{CH}_{3} \mathrm{CN}\right)_{4} \mathrm{PF}_{6}(5 \mathrm{~mol} \%)$, ligand $(7 \mathrm{~mol} \%)$, DIPEA (0.6 mmol, 3 equiv.), THF $(1 \mathrm{~mL}), \mathrm{rt}^{b}{ }^{b}$ Isolated yield. ${ }^{c}$ All chiral ligands provide product with less than $5 \%$ ee.
Table 2 Substrate scope of 1,3-enynes ${ }^{a}$

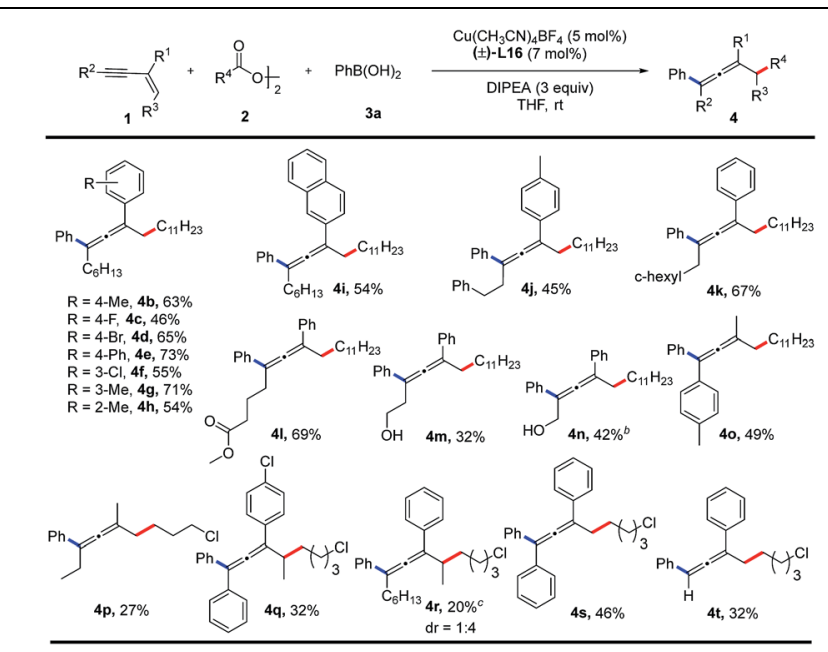

${ }^{a}$ Reaction conditions: 1 ( $0.2 \mathrm{mmol}, 1$ equiv.), 2 ( $0.3 \mathrm{mmol}, 1.5$ equiv.), 3a (0.6 mmol, 3 equiv.), $\mathrm{Cu}\left(\mathrm{CH}_{3} \mathrm{CN}\right)_{4} \mathrm{BF}_{4}(5 \mathrm{~mol} \%)$, ligand $(7 \mathrm{~mol} \%)$, DIPEA (0.6 mmol, 3 equiv.), THF $(1 \mathrm{~mL})$, rt. ${ }^{b}$ Yield after deprotection of the TMS ether in situ. ${ }^{c}$ The dr value was determined by GC-MS analysis.

a methyl group. Internal alkenes can also participate in the reaction, albeit with relatively lower yields of the corresponding products (4q, $\mathbf{4 r})$. Diphenyl substituted 1,3-enyne affords a triphenyl allene (4s) in $46 \%$ yield. A terminal alkyne can also be employed in this reaction and provides the corresponding product (4t) in $32 \%$ yield. The accompanied side reactions toward the terminal $\mathrm{C}(\mathrm{sp})-\mathrm{H}$ bond might be responsible for the low yield.

The substrate scope of alkyl diacyl peroxides was studied (Table 3). Primary alkyl diacyl peroxides functionalized with halide, carbonyl, ester, alkenyl or adamantanyl groups are converted into the desired products (5a-5i) in $49-72 \%$ yields. Furthermore, secondary alkyl diacyl peroxides can also be employed in the reaction, providing the corresponding products $(\mathbf{5 j}, \mathbf{5 k})$ in moderate yields.

Finally, we examined the substrate scope of aryl boronic acids in this transformation (Table 4). A range of aryl boronic acids bearing substituent(s) such as phenyl group, methyl group, chloride, or fluoride, can afford the desired products (6a-6h) in $35-77 \%$ yields. Product $\mathbf{6 i}$ bearing a naphthyl group is formed in $61 \%$ yield. Heterocyclic aryl groups, such as thienyl, are also compatible with this reaction, and the corresponding product $\mathbf{6 j}$ is obtained in $69 \%$ yield. However, alkyl boronic acids are unreactive.

The synthetic applications of this method have been demonstrated (Fig. 2). The allene (4a) can react with $N$-iodosuccinimide (NIS) to afford an indenyl iodide in $75 \%$ yield. ${ }^{6 l}$ When treated under acidic reaction conditions, the allene (6i) is transformed into the $1 H$-indene (8) in $60 \%$ yield. Moreover, proton- or NIS-mediated cyclization of $\mathbf{4 p}$ afford $2 \mathrm{H}$-pyrans $(\mathbf{9}$, 10) in $51 \%$ and $56 \%$ yields, respectively.

Preliminary mechanistic studies were carried out in an effort to obtain more information about the mechanism of this 
Table 3 Substrate scope of alkyl diacyl peroxides ${ }^{a}$

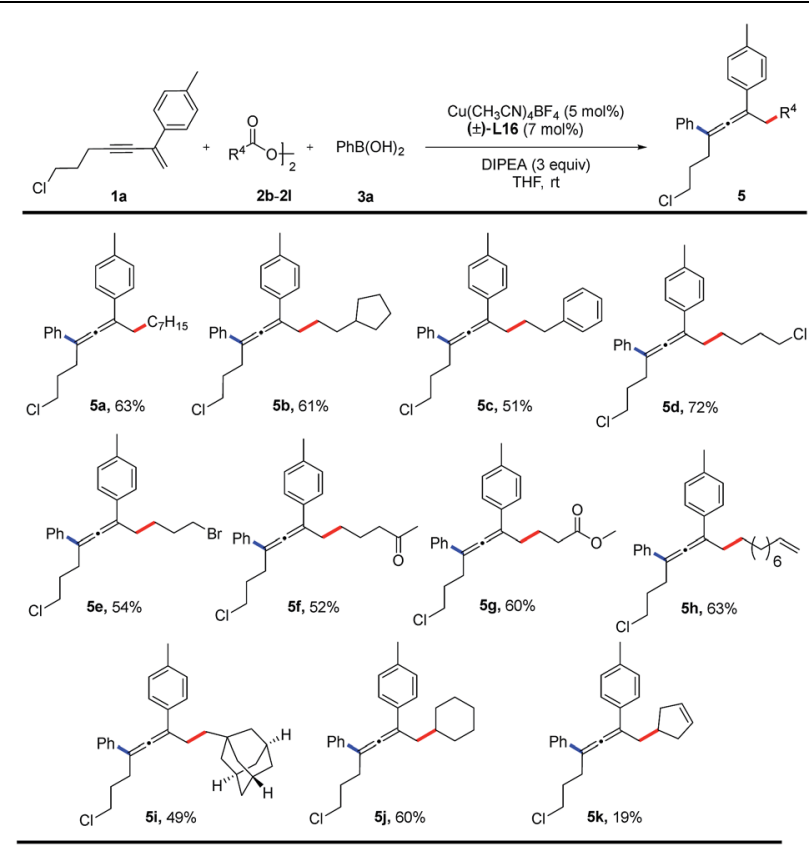

${ }^{a}$ Reaction conditions: $1 \mathrm{a}$ ( $0.2 \mathrm{mmol}, 1$ equiv.), 2 ( $0.3 \mathrm{mmol}, 1.5$ equiv.), 3a (0.6 mmol, 3 equiv.), $\mathrm{Cu}\left(\mathrm{CH}_{3} \mathrm{CN}\right)_{4} \mathrm{BF}_{4}(5 \mathrm{~mol} \%)$, ligand $(7 \mathrm{~mol} \%)$, DIPEA (0.6 mmol, 3 equiv.), THF ( $1 \mathrm{~mL})$, rt.

Table 4 Substrate scope of aryl boronic acid ${ }^{a}$

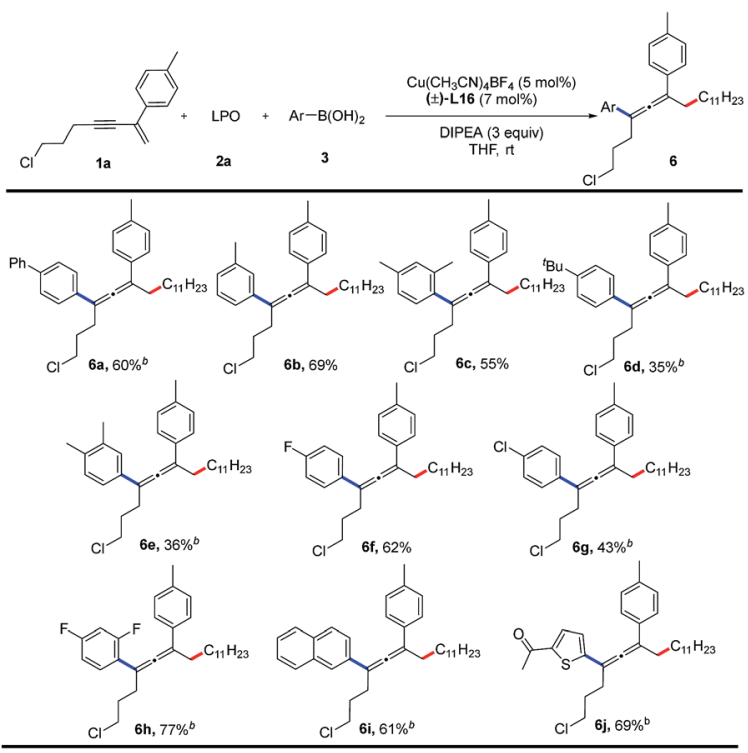

${ }^{a}$ Reaction conditions: $1 \mathrm{a}(0.2 \mathrm{mmol}, 1$ equiv.), $2 \mathrm{a}(0.3 \mathrm{mmol}, 1.5$ equiv.), 3 (0.6 mmol, 3 equiv.), $\mathrm{Cu}\left(\mathrm{CH}_{3} \mathrm{CN}\right)_{4} \mathrm{BF}_{4}(5 \mathrm{~mol} \%)$, ligand $(7 \mathrm{~mol} \%)$, DIPEA (0.6 mmol, 3 equiv.), THF $(1 \mathrm{~mL})$, rt. ${ }^{b}$ Reaction conditions: 1a ( $0.2 \mathrm{mmol}, 1$ equiv.), $2 \mathrm{a}(0.3 \mathrm{mmol}, 1.5$ equiv.), 3 ( $0.6 \mathrm{mmol}, 3$ equiv.), $\mathrm{Cu}\left(\mathrm{CH}_{3} \mathrm{CN}\right)_{4} \mathrm{BF}_{4}(5 \mathrm{~mol} \%)$, ligand (7 mol\%), DMF (1 mL), THF (1 mL), rt.

reaction (Fig. 3). First, an experiment with three equivalents of 2,2,6,6-tetra-methyl-1-piperidinyloxy (TEMPO), a radicaltrapping reagent, was performed. The expected product (4a)

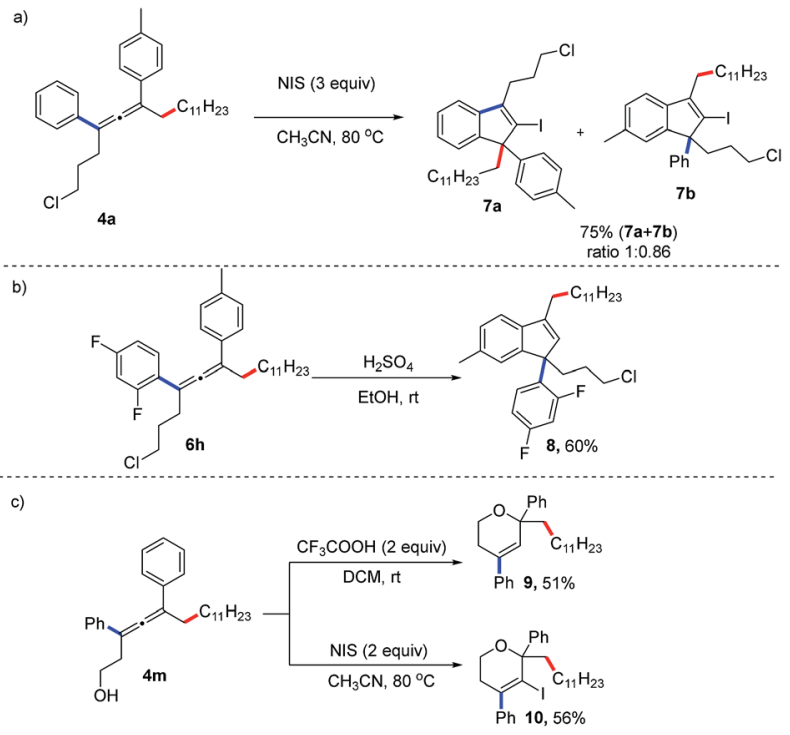

Fig. 2 Synthetic applications.

was not formed, and compound $\mathbf{1 1}$ was identified by GC-MS analysis, indicating the formation of an alkyl radical species (Fig. 3a). Second, radical clock experiments with three different substrates were performed. Interestingly, substrates $\mathbf{1 2}$ and $\mathbf{1 4}$ were found only to produce allenyl compounds $(\mathbf{1 3}, \mathbf{1 5})$ in moderate yields. No ring-opening product from 12 or ringclosing product from $\mathbf{1 4}$ was detected, suggesting that the rate

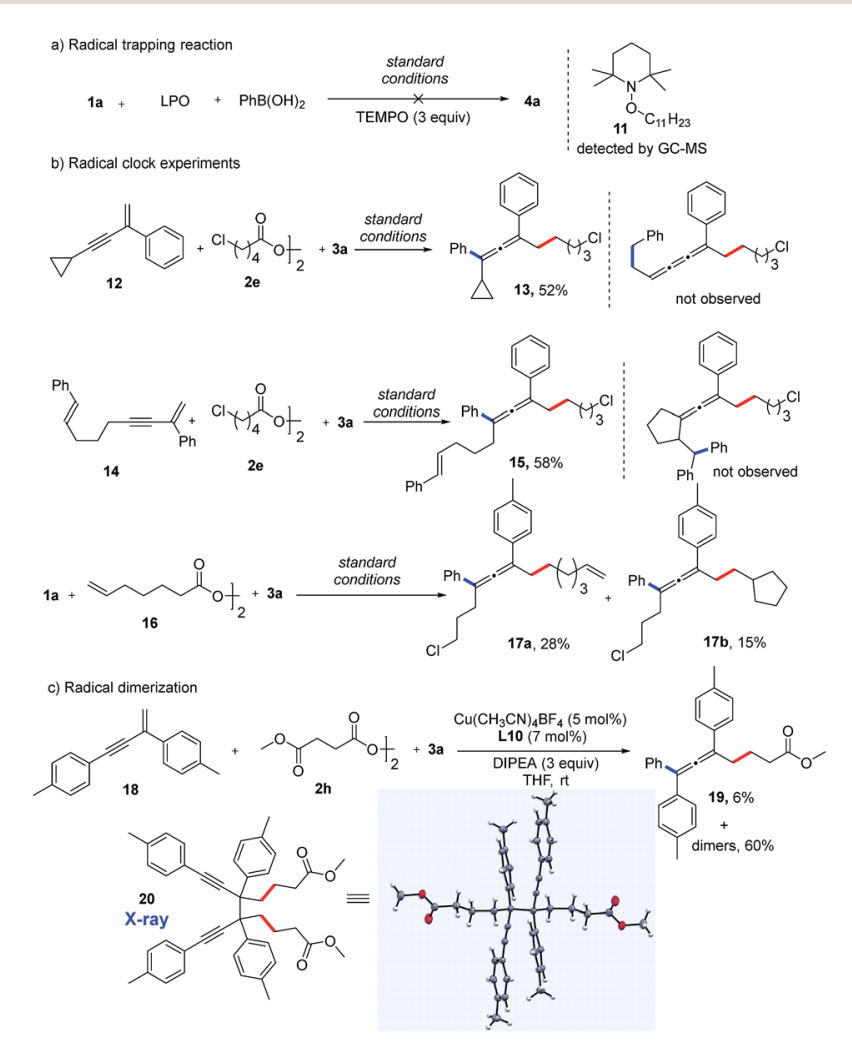

Fig. 3 Mechanistic studies. 


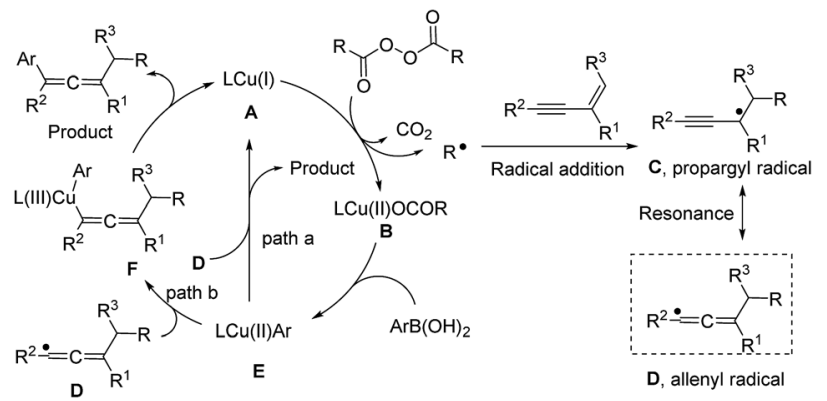

Fig. 4 Plausible catalytic cycle.

of formation of the allene product is the much faster reaction (Fig. 3b). When an alkyl diacyl peroxide (16) was used as the alkylating reagent, both the vinylated allene (17a) and cyclopentylated allene (17b) were obtained. This reaction further supports the possibility of the formation of alkyl radicals. Notably, a trace amount the homocoupling product was detected in almost all of the reactions. ${ }^{18}$ More of the homocoupling product was observed with bidentate bisoxazoline ligands. When using L10 as a bidentate ligand, a mixture of homocoupling dimers was obtained in $60 \%$ yield along with $6 \%$ yield of the allene product 19 (Fig. 3c). Remarkably, the propargyl radical dimer $\mathbf{2 0}$ was crystallized from the mixture and the structure was confirmed by X-ray crystallography. This result suggests the existence of a propargyl radical which is a resonance structure of allenyl radical. ${ }^{15 b}$

Based on these studies, a plausible mechanism is proposed and is shown in Fig. 4. The Cu(I) species (A) reacts with an alkyl diacyl peroxide generating an alkyl radical and a $\mathrm{Cu}(\mathrm{II})$ species (B) via a single electron transfer. Then the alkyl radical attacks a 1,3-enyne to give a propargyl radical (C), which can be converted to the allenyl radical species (D). The $\mathrm{Cu}$ (II) species (B) can exchange its ligand with $\mathrm{ArB}(\mathrm{OH})_{2}$ to generate the $\mathrm{Ar}-\mathrm{Cu}$ (II) species (E). Two possible pathways might be involved in the catalytic cycle: path a (outer-sphere) is the radical homolytic substitution interaction ${ }^{\mathbf{1 9}}$ between the $\mathrm{Ar}-\mathrm{Cu}(\mathrm{II})$ species (E) and the allenyl radical, leading to the product and regenerating the copper catalyst. In path b (inner-sphere), a $\mathrm{Cu}(\mathrm{II})$ species (E) combines with the allenyl radical species (D) to form a $\mathrm{Cu}$ (III) intermediate $(\mathbf{F})$, which by reductive elimination, generates the target product and the $\mathrm{Cu}(\mathrm{I})$ species (A). As shown in the mechanistic cycle, the three-component reaction involves 1,3enyne as a neutral substrate, aryl boronic acid as a mild nucleophile, and alkyl peroxide as an electrophile in the absence of extra oxidant or reductant. The alkyl peroxide can generate an alkyl radical and oxidize the $\mathrm{Cu}(\mathrm{I})$ to $\mathrm{Cu}(\mathrm{II})$, a subsequent oxidant to turn over the reaction. Thus, the alkyl peroxide acts as, more precisely, a masked alkyl electrophile.

\section{Conclusions}

In conclusion, we have developed a copper-catalyzed 1,4-alkylarylation of 1,3-enynes which affords diverse tetra-substituted allenes under mild reaction conditions. Functionalized alkyl diacyl peroxides are used as masked alkyl electrophiles and aryl boronic acids as aryl nucleophiles. The tetrasubstituted allenes obtained in this way can be easily transformed into useful specific compounds such as $1 H$-indenes, $2 H$-pyrans, and their iodo-derivatives. Preliminary mechanistic studies suggest the involvement of radical species and a radical addition mechanism for this reaction is proposed.

\section{Conflicts of interest}

There are no conflicts to declare.

\section{Acknowledgements}

We thank the National Key R\&D Program of China (Grant No. 2017YFA0700103), the NSFC (Grant No. 21502191, 21672213, 21871258), the Strategic Priority Research Program of the Chinese Academy of Sciences (Grant No. XDB20000000), the Haixi Institute of CAS (Grant No. CXZX-2017-P01) for financial support. The X-ray crystallographic coordinates for structure reported in this article have been deposited at the Cambridge Crystallographic Data Centre (CCDC), under deposition number CCDC 1883091.†

\section{Notes and references}

1 (a) N. Krause, A. Stephen and K. Hashimi, Modern Allene Chemistry, Wiley-VCH, Weinheim, 2004; (b) A. HoffmannRöder and N. Krause, Angew. Chem., Int. Ed., 2004, 43, 1196; (c) S. Ma, Chem. Rev., 2005, 105, 2829; (d) K. M. Brummond and J. E. DeForrest, Synthesis, 2007, 795; (e) S. Ma, Acc. Chem. Res., 2009, 42, 1679; (f) C. Aubert, L. Fensterbank, P. Garcia, M. Malacria and A. Simonneau, Chem. Rev., 2011, 111, 1954; $(g)$ S. Yu and S. Ma, Angew. Chem., Int. Ed., 2012, 51, 3074; (h) C.-Y. Wang, G.-H. Pan, F. Chen and J.-H. Li, Chem. Commun., 2017, 53, 4730.

2 (a) S. Yu and S. Ma, Chem. Commun., 2011, 47, 5384; (b) J. Ye and S. Ma, Org. Chem. Front., 2014, 1, 1210.

3 (a) B. D. Sherry and F. D. Toste, J. Am. Chem. Soc., 2004, 126, 15978; (b) Z. Li, V. Boyarskikh, J. H. Hansen, J. Autschbach, D. G. Musaev and H. M. Davies, J. Am. Chem. Soc., 2012, 134, 15497; (c) D. A. Mundal, K. E. Lutz and R. J. Thomson, J. Am. Chem. Soc., 2012, 134, 5782; (d) Y. Jiang, A. B. Diagne, R. J. Thomson and S. E. Schaus, J. Am. Chem. Soc., 2017, 139, 1998; (e) H. Liu, D. Leow, K. W. Huang and C. H. Tan, J. Am. Chem. Soc., 2009, 131, 7212.

4 (a) H. Ito, Y. Sasaki and M. Sawamura, J. Am. Chem. Soc., 2008, 130, 15774; (b) H. Ohmiya, U. Yokobori, Y. Makida and M. Sawamura, Org. Lett., 2011, 13, 6312; (c) M. Yang, N. Yokokawa, H. Ohmiya and M. Sawamura, Org. Lett., 2012, 14, 816; (d) S. N. Kessler and J. E. Backvall, Angew. Chem., Int. Ed., 2016, 55, 3734.

5 (a) J. W. Han, N. Tokunaga and T. Hayashi, J. Am. Chem. Soc., 2001, 123, 12915; (b) C. Luken and C. Moberg, Org. Lett., 2008, 10, 2505; (c) T. Nishimura, H. Makino, M. Nagaosa and T. Hayashi, J. Am. Chem. Soc., 2010, 132, 12865; (d) Y. Xiao and J. Zhang, Chem. Commun., 2010, 46, 752; (e) 
Y. Mori, G. Onodera and M. Kimura, Chem. Lett., 2014, 43, 97; $(f)$ A. Nishimura, E. Tamai, M. Ohashi and S. Ogoshi, Chem.-Eur. J., 2014, 20, 6613; $(g)$ Y. Huang, J. Del Pozo, S. Torker and A. H. Hoveyda, J. Am. Chem. Soc., 2018, 140, 2643; (h) H. L. Sang, S. Yu and S. Ge, Org. Chem. Front., 2018, 5, 1284; (i) X. Zhu, W. Deng, M. F. Chiou, C. Ye, W. Jian, Y. Zeng, Y. Jiao, L. Ge, Y. Li, X. Zhang and H. Bao, J. Am. Chem. Soc., 2019, 141, 548; (j) D.-W. Gao, Y. Xiao, M. Liu, Z. Liu, M. K. Karunananda, J. S. Chen and K. M. Engle, ACS Catal., 2018, 8, 3650; (k) S. Yu, H. L. Sang, S.-Q. Zhang, X. Hong and S. Ge, Commun. Chem., 2018, 1, 64. 6 (a) E. Mainetti, L. Fensterbank and M. Malacria, Synlett, 2002, 923; (b) Z. Yang, W. J. Hao, S. L. Wang, J. P. Zhang, B. Jiang, G. Li and S. J. Tu, J. Org. Chem., 2015, 80, 9224; (c) S. Ma and Q. He, Angew. Chem., Int. Ed., 2004, 43, 988; (d) M. Ogasawara, Y. Ge, K. Uetake and T. Takahashi, Org. Lett., 2005, 7, 5697; (e) W. Zhang, H. Xu, H. Xu and W. Tang, J. Am. Chem. Soc., 2009, 131, 3832; $(f)$ D. C. Whitehead, R. Yousefi, A. Jaganathan and B. Borhan, J. Am. Chem. Soc., 2010, 132, 3298; (g) H. Qian, X. Yu, J. Zhang and J. Sun, J. Am. Chem. Soc., 2013, 135, 18020; $(h)$ Z. Wang, X. Li and Y. Huang, Angew. Chem., Int. Ed., 2013, 52, 14219; ( $i$ ) M. Wang, Z. L. Liu, X. Zhang, P. P. Tian, Y. H. Xu and T. P. Loh, J. Am. Chem. Soc., 2015, 137, 14830; (j) W. D. Chu, L. Zhang, Z. Zhang, Q. Zhou, F. Mo, Y. Zhang and J. Wang, J. Am. Chem. Soc., 2016, 138, 14558; (k) J. Zhao and K. J. Szabo, Angew. Chem., Int. Ed., 2016, 55, 1502; (l) D. Qian, L. Wu, Z. Lin and J. Sun, Nat. Commun., 2017, 8, 567; (m) M. Guisan-Ceinos, V. Martin-Heras, R. Soler-Yanes, D. J. Cardenas and M. Tortosa, Chem. Commun., 2018, 54, 8343; (n) P. H. Poulsen, Y. Li, V. H. Lauridsen, D. K. B. Jorgensen, T. A. Palazzo, M. Meazza and K. A. Jorgensen, Angew. Chem., Int. Ed., 2018, 57, 10661; (o) N. Liu, Y. Zhi, J. Yao, J. Xing, T. Lu and X. Dou, Adv. Synth. Catal., 2018, 360, 642.

7 (a) J. Zhao, Y. Liu, Q. He, Y. Li and S. Ma, Chem.-Eur. J., 2009, 15, 11361; (b) S. Ma, Q. He and X. Jin, Synlett, 2005, 514.

8 H. Todo, J. Terao, H. Watanabe, H. Kuniyasu and N. Kambe, Chem. Commun., 2008, 1332.

9 Y. Tomida, A. Nagaki and J.-i. Yoshida, J. Am. Chem. Soc., 2011, 133, 3744.

10 (a) Y. Yasu, T. Koike and M. Akita, Adv. Synth. Catal., 2012, 354, 3414; (b) H. Huang, G. Zhang, L. Gong, S. Zhang and Y. Chen, J. Am. Chem. Soc., 2014, 136, 2280; (c) J. C. Tellis,
D. N. Primer and G. A. Molander, Science, 2014, 345, 433; (d) H. Huang, K. Jia and Y. Chen, Angew. Chem., Int. Ed., 2015, 54, 1881; (e) T. Koike and M. Akita, Org. Biomol. Chem., 2016, 14, 6886; (f) G. X. Li, C. A. Morales-Rivera, Y. Wang, F. Gao, G. He, P. Liu and G. Chen, Chem. Sci., 2016, 7, 6407; (g) L. Zhang and Z. Q. Liu, Org. Lett., 2017, 19, 6594; (h) K. Duan, X. Yan, Y. Liu and Z. Li, Adv. Synth. Catal., 2018, 360, 2781; (i) W. Li, J. K. Boon and Y. Zhao, Chem. Sci., 2018, 9, 600.

11 (a) J. T. Edwards, R. R. Merchant, K. S. McClymont, K. W. Knouse, T. Qin, L. R. Malins, B. Vokits, S. A. Shaw, D. H. Bao, F. L. Wei, T. Zhou, M. D. Eastgate and P. S. Baran, Nature, 2017, 545, 213; (b) J. Cornella, J. T. Edwards, T. Qin, S. Kawamura, J. Wang, C. M. Pan, R. Gianatassio, M. Schmidt, M. D. Eastgate and P. S. Baran, J. Am. Chem. Soc., 2016, 138, 2174.

12 (a) B. Qian, S. Chen, T. Wang, X. Zhang and H. Bao, J. Am. Chem. Soc., 2017, 139, 13076; (b) W. Jian, L. Ge, Y. Jiao, B. Qian and H. Bao, Angew. Chem., Int. Ed., 2017, 56, 3650.

13 (a) Y. Li, Y. Han, H. Xiong, N. Zhu, B. Qian, C. Ye, E. A. Kantchev and H. Bao, Org. Lett., 2016, 18, 392; (b) C. Ye, Y. Li and H. Bao, Adv. Synth. Catal., 2017, 359, 3720.

14 H. Zhou, L. Ge, J. Song, W. Jian, Y. Li, C. Li and H. Bao, iScience, 2018, 3, 255.

15 (a) N. J. Reilly, D. L. Kokkin, M. Nakajima, K. Nauta, S. H. Kable and T. W. Schmidt, J. Am. Chem. Soc., 2008, 130, 3137; (b) M. M. Hansmann, M. Melaimi and G. Bertrand, J. Am. Chem. Soc., 2017, 139, 15620.

16 (a) C. Alameda-Angulo, B. Quiclet-Sire and S. Z. Zard, Tetrahedron Lett., 2006, 47, 913; (b) H. G. Benson, A. J. Bowles, A. Hudson and R. A. Jackson, Mol. Phys., 1971, 20, 713; (c) J. Terao, F. Bando and N. Kambe, Chem. Commun., 2009, 7336; (d) F. Wang, D. Wang, Y. Zhou, L. Liang, R. Lu, P. Chen, Z. Lin and G. Liu, Angew. Chem., Int. Ed., 2018, 57, 7140.

17 (a) D. Wang, L. Wu, F. Wang, X. Wan, P. Chen, Z. Lin and G. Liu, J. Am. Chem. Soc., 2017, 139, 6811; (b) L. Wu, F. Wang, X. Wan, D. Wang, P. Chen and G. Liu, J. Am. Chem. Soc., 2017, 139, 2904.

18 F. Wang, D. Wang, X. Wan, L. Wu, P. Chen and G. Liu, J. Am. Chem. Soc., 2016, 138, 15547.

19 (a) C. H. Schiesser and L. M. Wild, Tetrahedron, 1996, 52, 13265; (b) S. Tang, P. Wang, H. Li and A. Lei, Nat. Commun., 2016, 7, 11676. 